\title{
An Adaptive Trajectory Tracking Controller of a Multi-joint Snake Robot Considering Non-holonomic Constraints
}

\section{Dongfang Li ( $\sim 188377985 @ q q . c o m$ )}

Beijing Institute of Technology https://orcid.org/0000-0001-9863-4172

\section{Chao Wang}

China north industries corp

\section{Hongbin Deng}

Beijing Institute of Technology

Jie Huang

Fuzhou University

\section{Research Article}

Keywords: Multi-joint snake robot, Backstepping method, adaptive trajectory tracking controller, stability

Posted Date: May 10th, 2021

DOI: https://doi.org/10.21203/rs.3.rs-458693/v1

License: (c) (i) This work is licensed under a Creative Commons Attribution 4.0 International License. Read Full License 


\section{Abstract}

Multi-joint snake robot is a vital reconnaissance, surveillance and attack weapon in national defence and military in the future. To study the trajectory tracking problem of a multi-joint snake robot with high redundancy and multi-degree of freedom in the plane, an adaptive trajectory tracking controller of a multijoint snake robot considering non-holonomic constraints is proposed in this paper. The adaptive trajectory tracking controller replaces unknown parameters in the environment wi t h estimated values, which effectively solves the negative effects caused by uncertain and time-varying environmental parameters in the process of the robot movement and realizes the stability of the controller. Firstly, a new dynamical model of a multi-joint snake robot is established through coordinate transformation. Secondly, the control objective of the controller of the multi-joint snake robot is established. Thirdly, the proposed controller of the multi-joint snake robot is designed by the Backsteppi $n$ g method to realize the control of the joint angle tracking error, link angle tracking error, actuator torque error and motion speed error of the robot. Then, a suitable Lyapunov function is found to verify the stability of the controller. Finally, through the MATLAB simulation and prototype experiment, the motion process of the multi-joint snake robot is observed, the trajectory tracking performance of the robot is analyzed, and the effectiveness of the adaptive trajectory tracking controller is verified.

\section{Full-text}

Due to technical limitations, full-text HTML conversion of this manuscript could not be completed. However, the manuscript can be downloaded and accessed as a PDF.

\section{Figures}

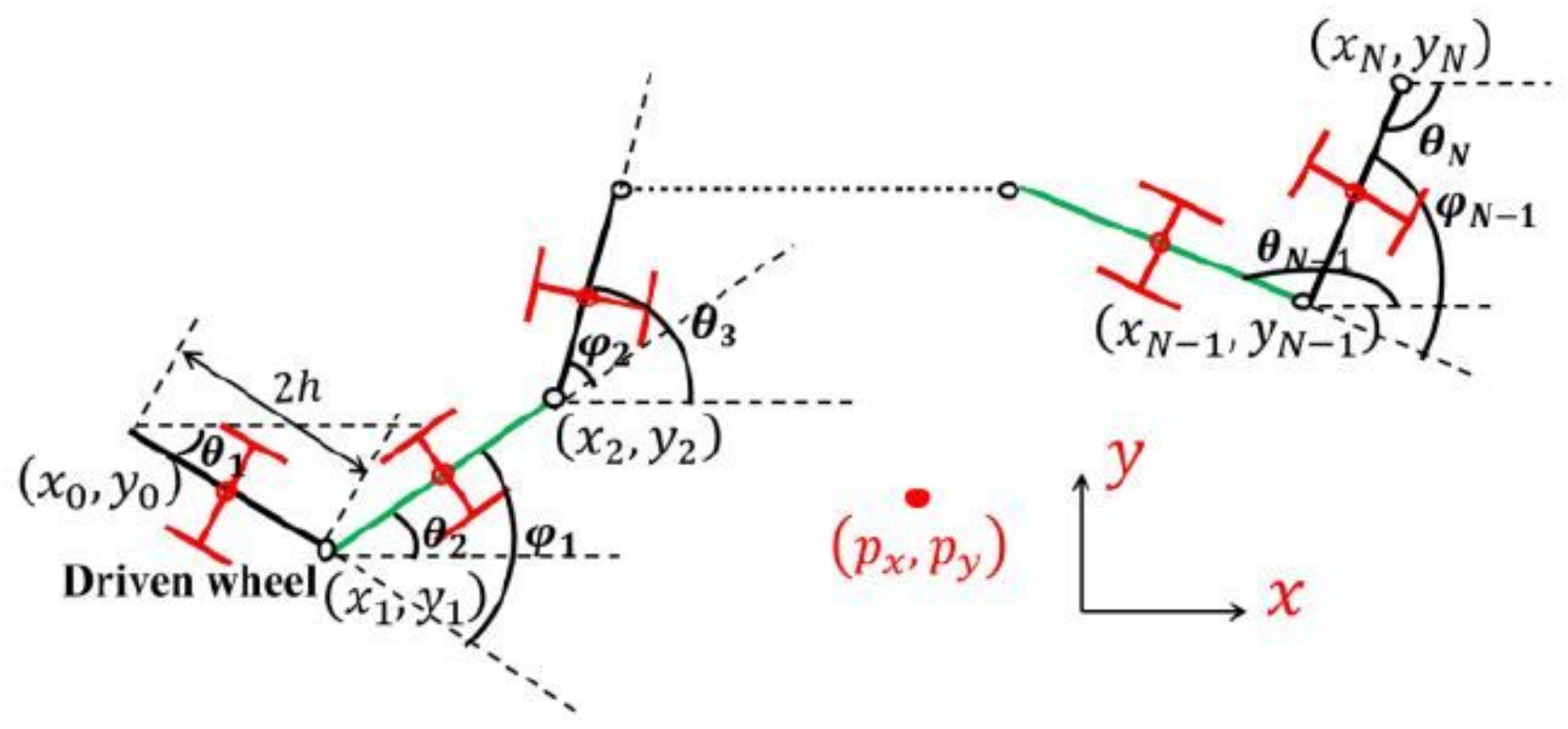

Figure 1 


\section{Dynamical model of a multi-joint snake robot}

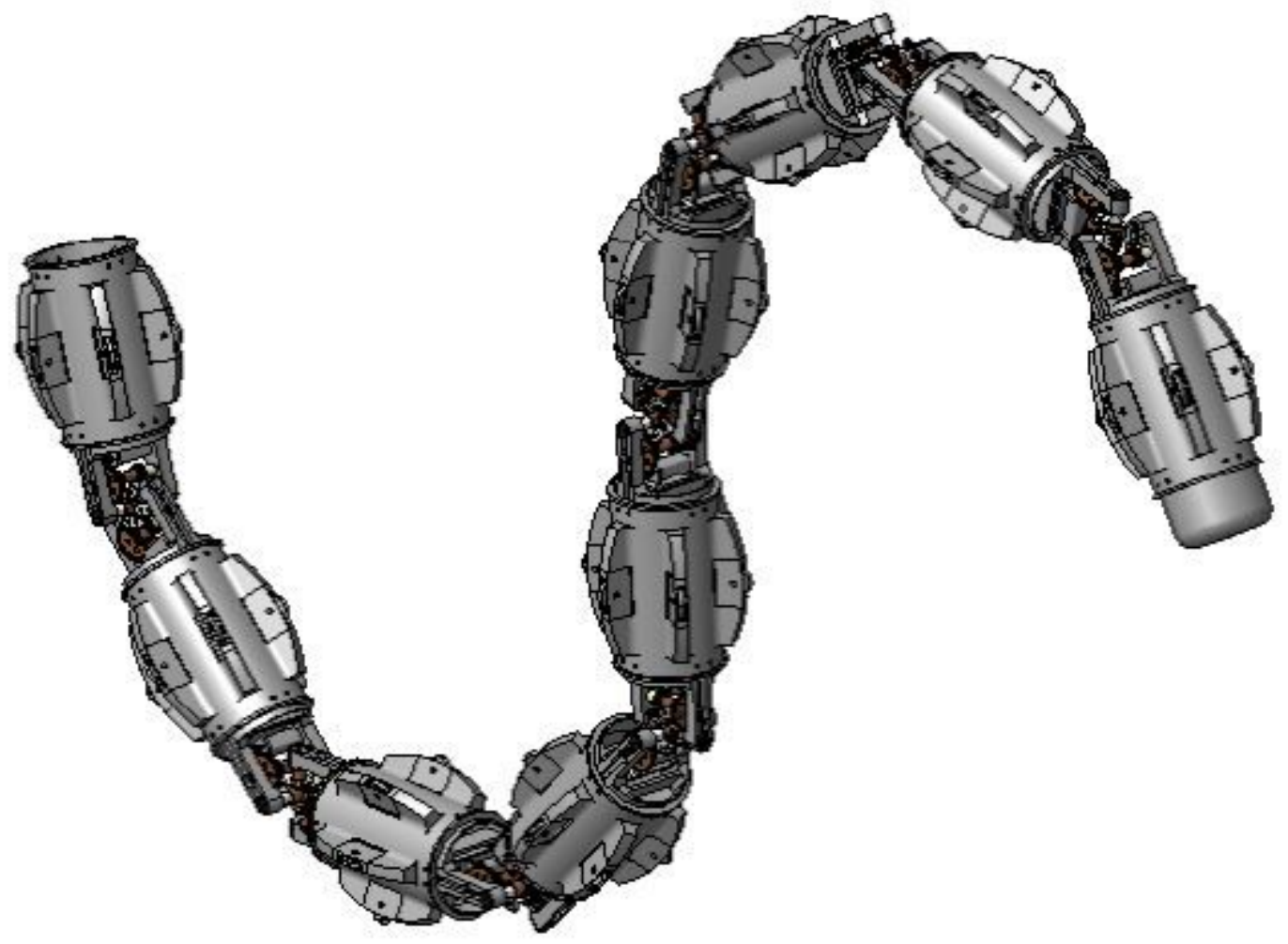

Figure 2

Multi-joint snake robot 


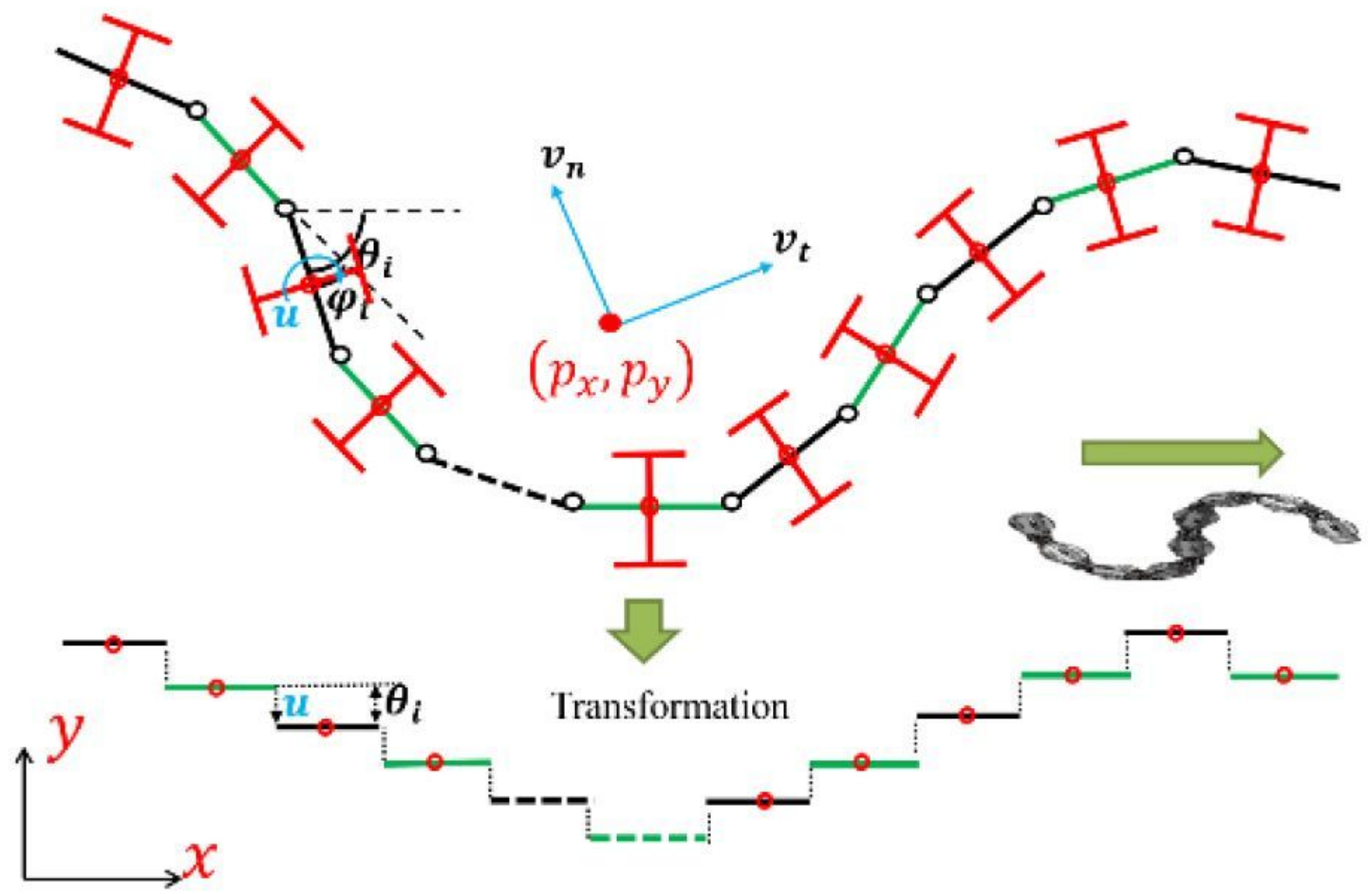

Figure 3

Coordinate transformation 


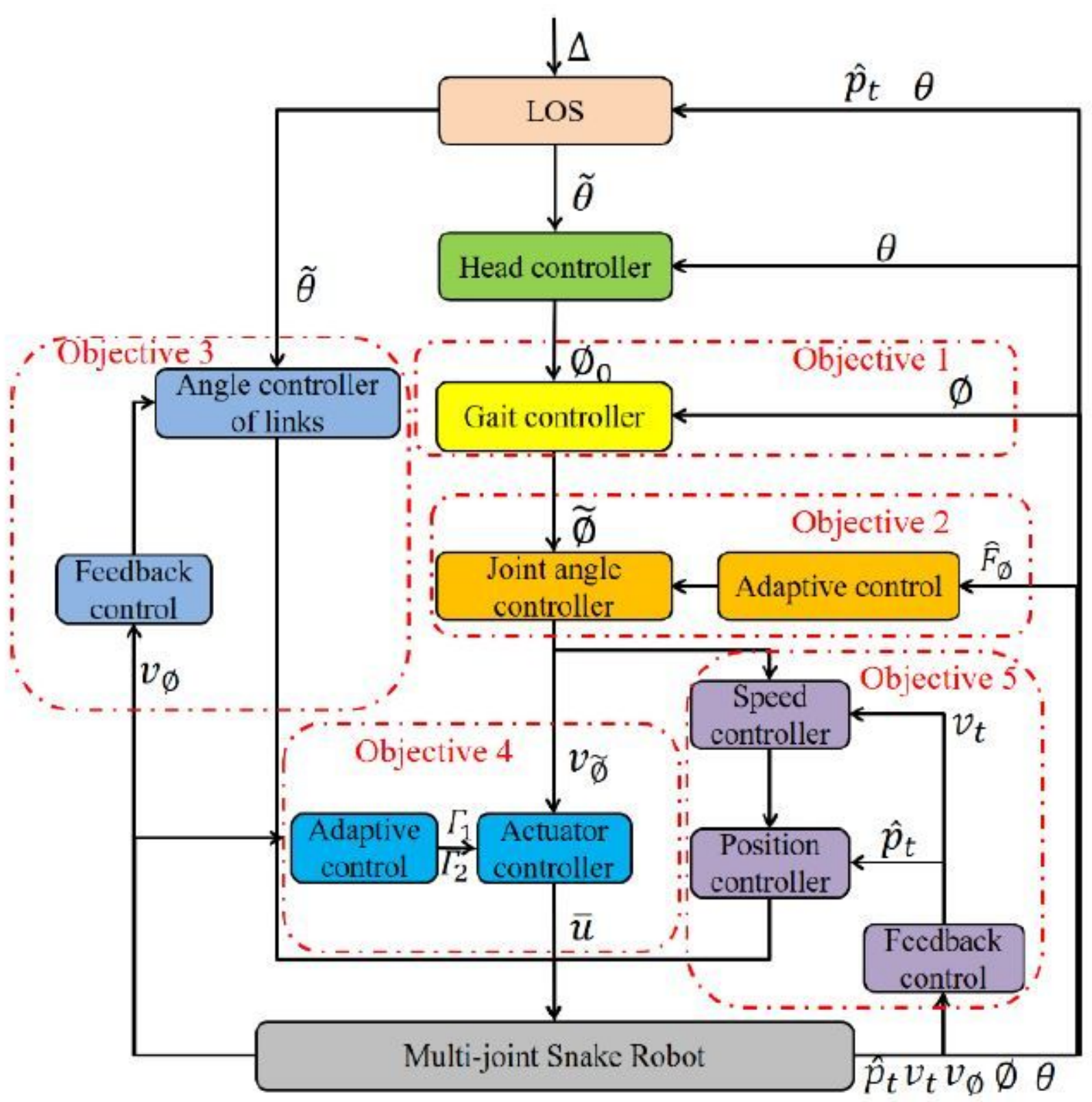

Figure 4

Adaptive trajectory tracking controller structure 


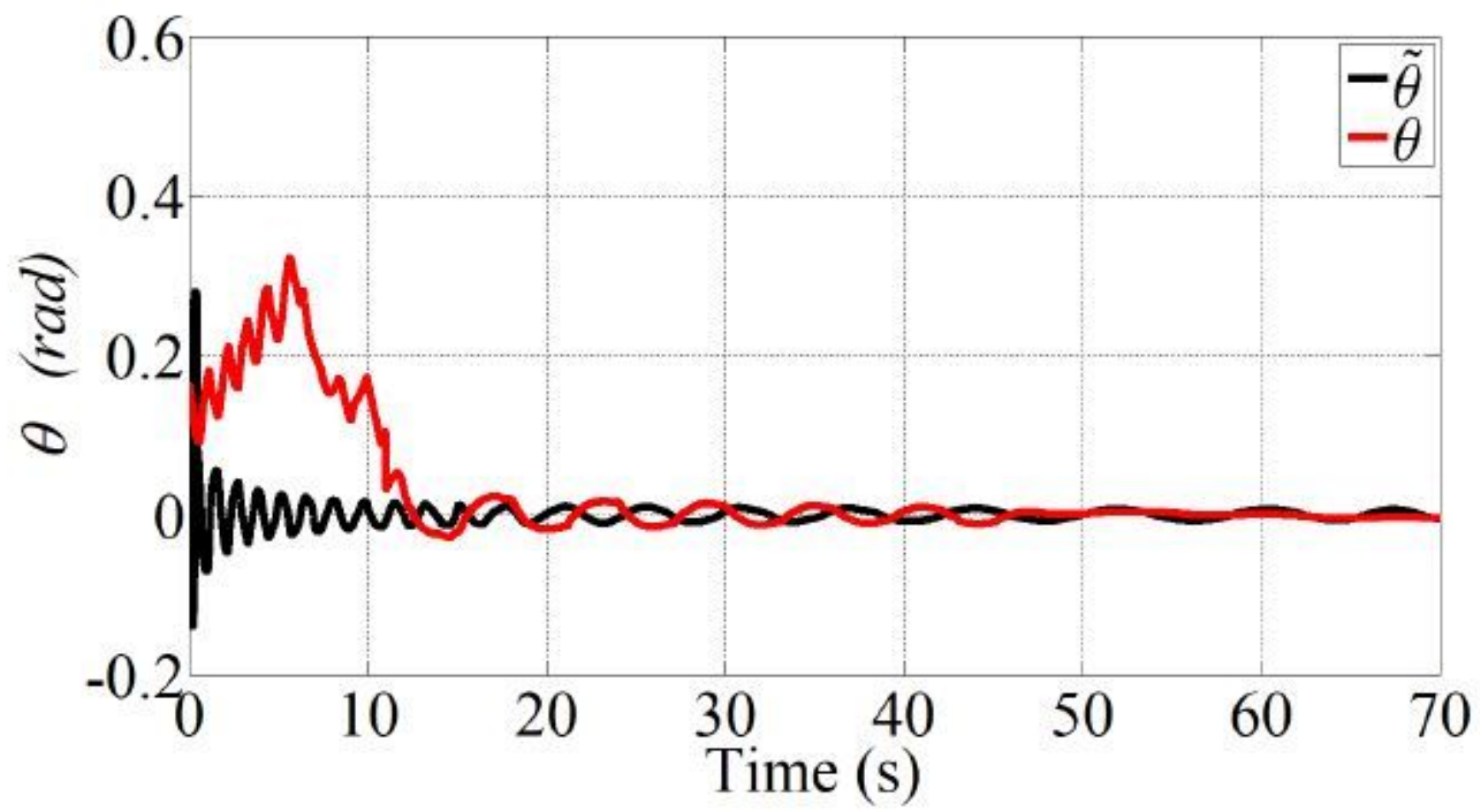

Figure 5

please see the manuscript file for the full caption

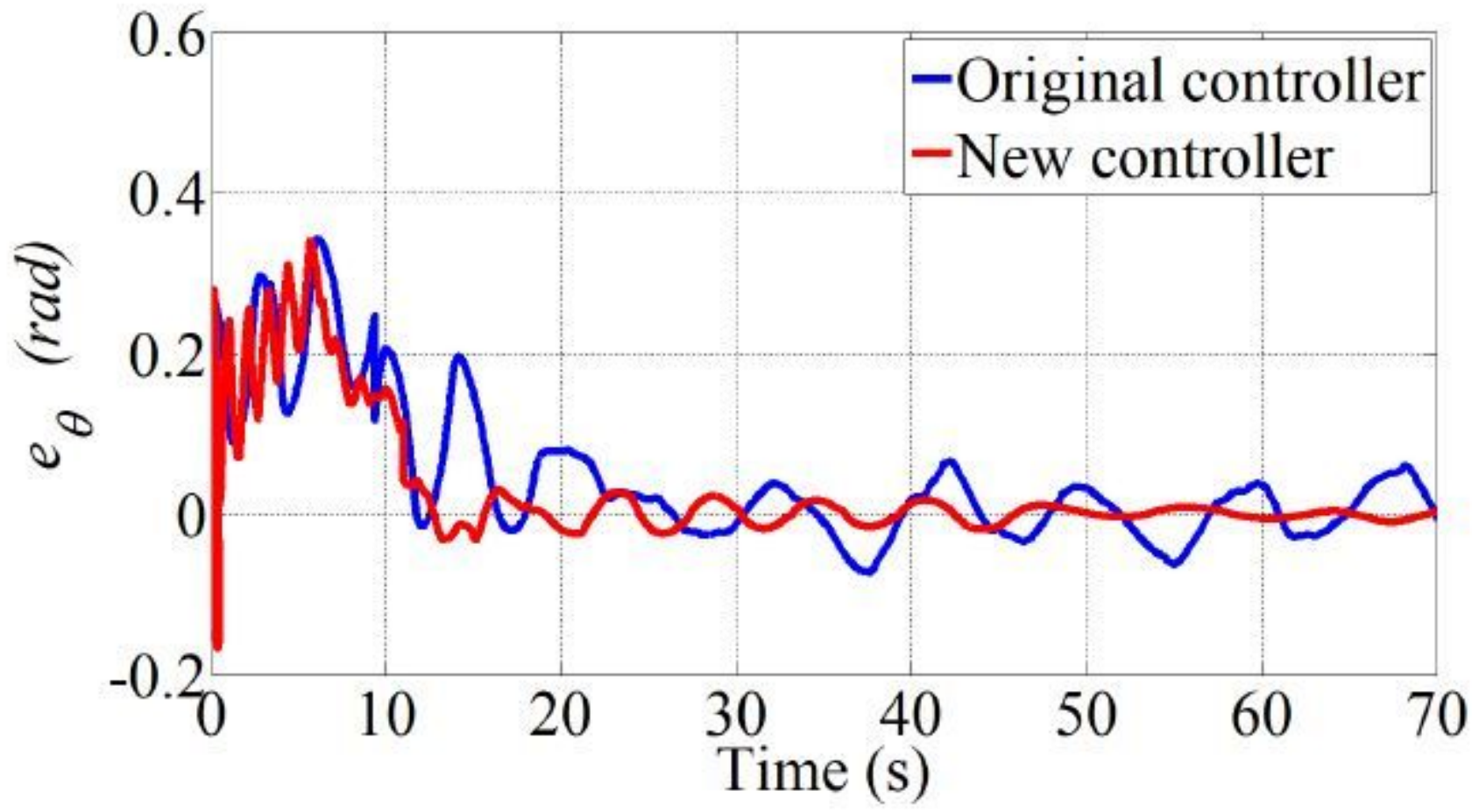

Figure 6 
please see the manuscript file for the full caption

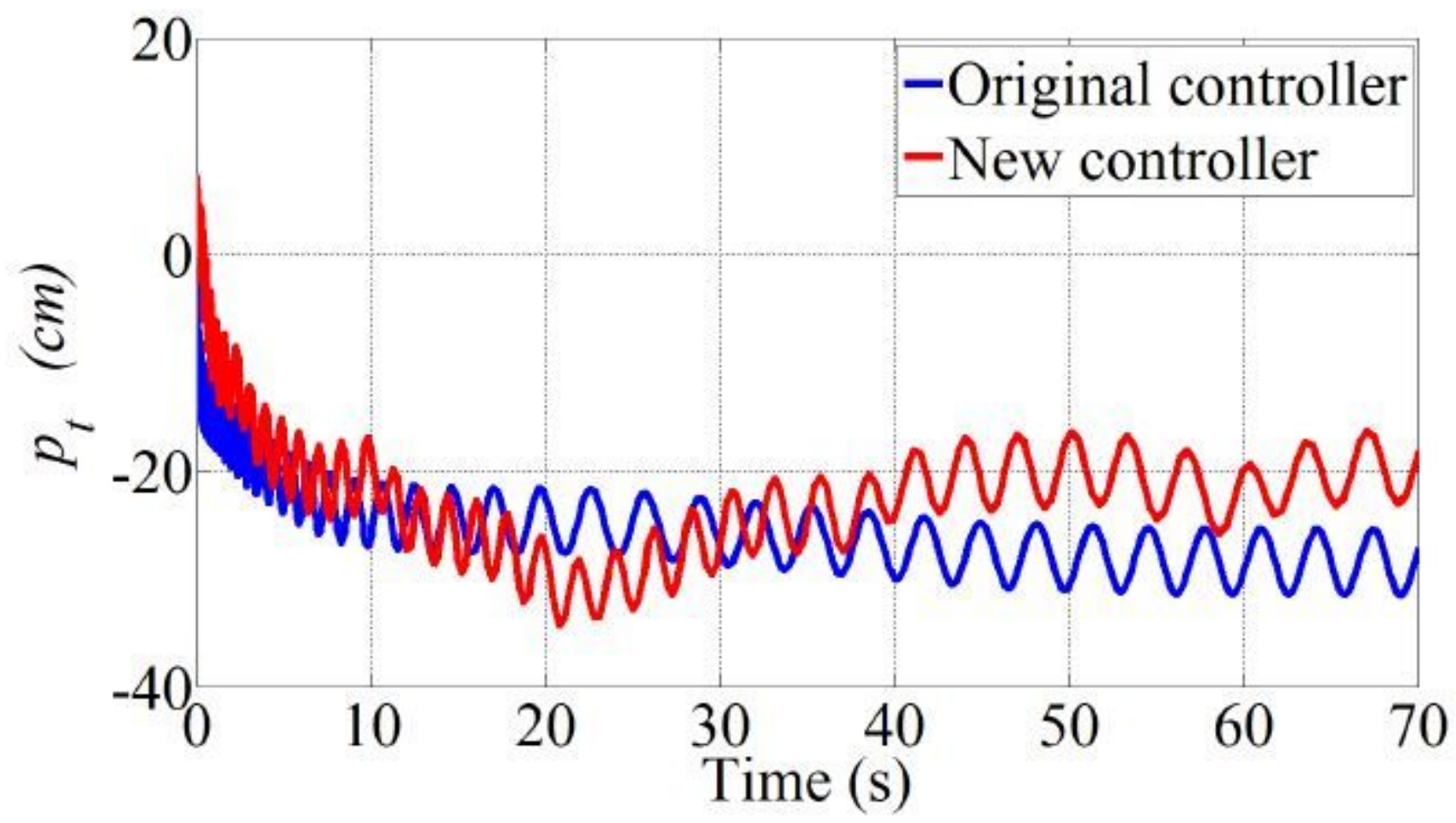

Figure 7

Centroid motion trajectory

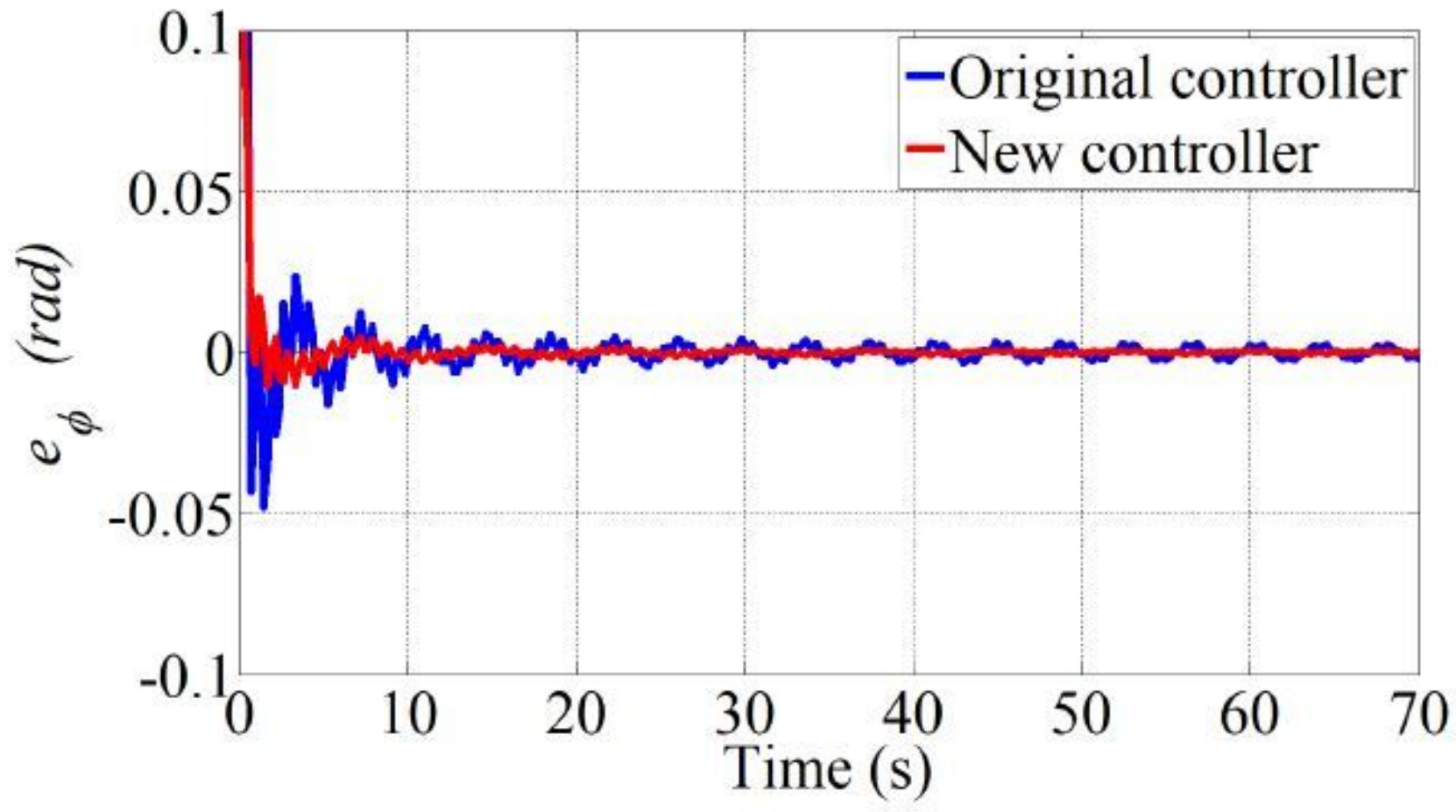


Figure 8

please see the manuscript file for the full caption

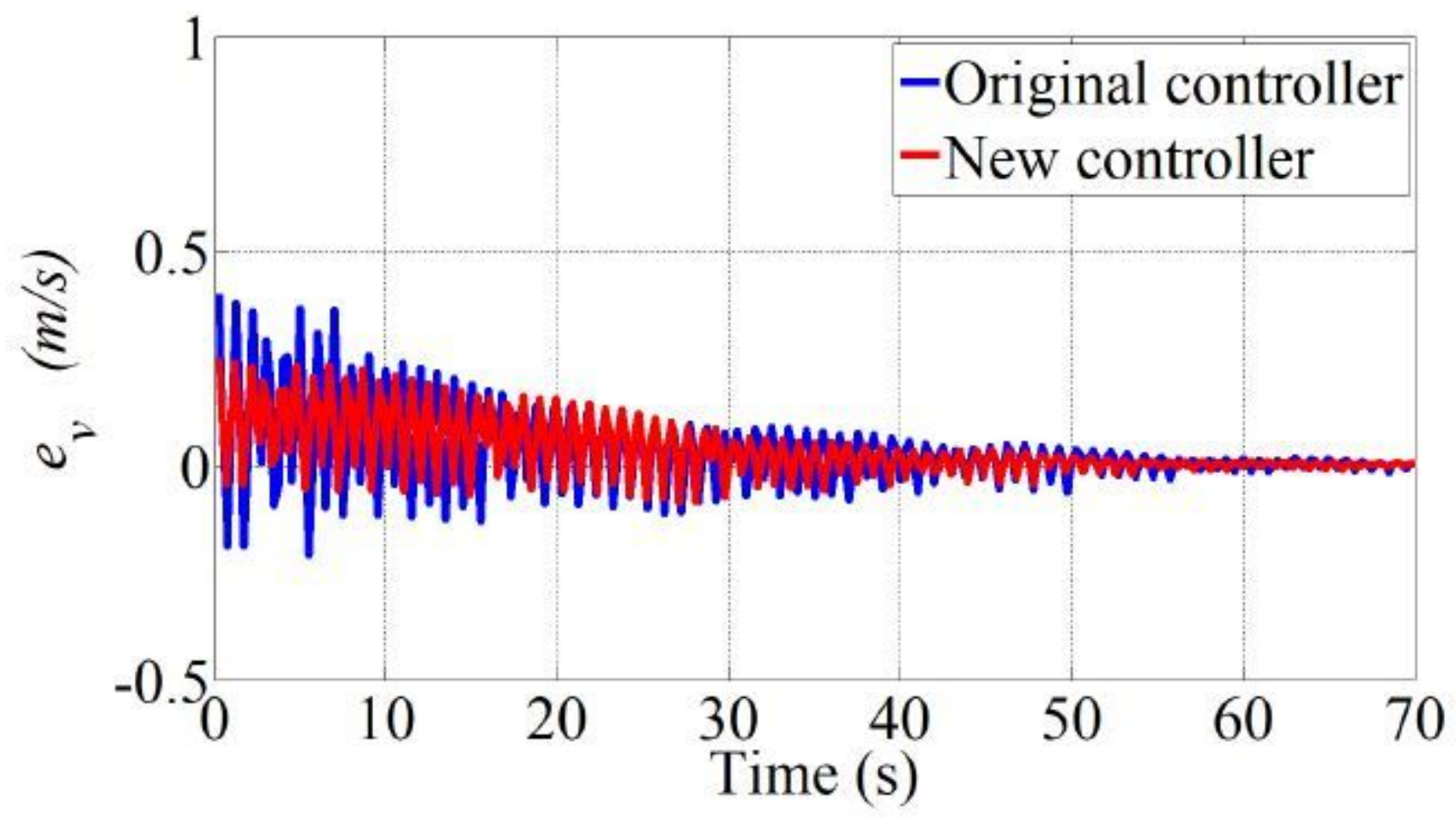

Figure 9

please see the manuscript file for the full caption 


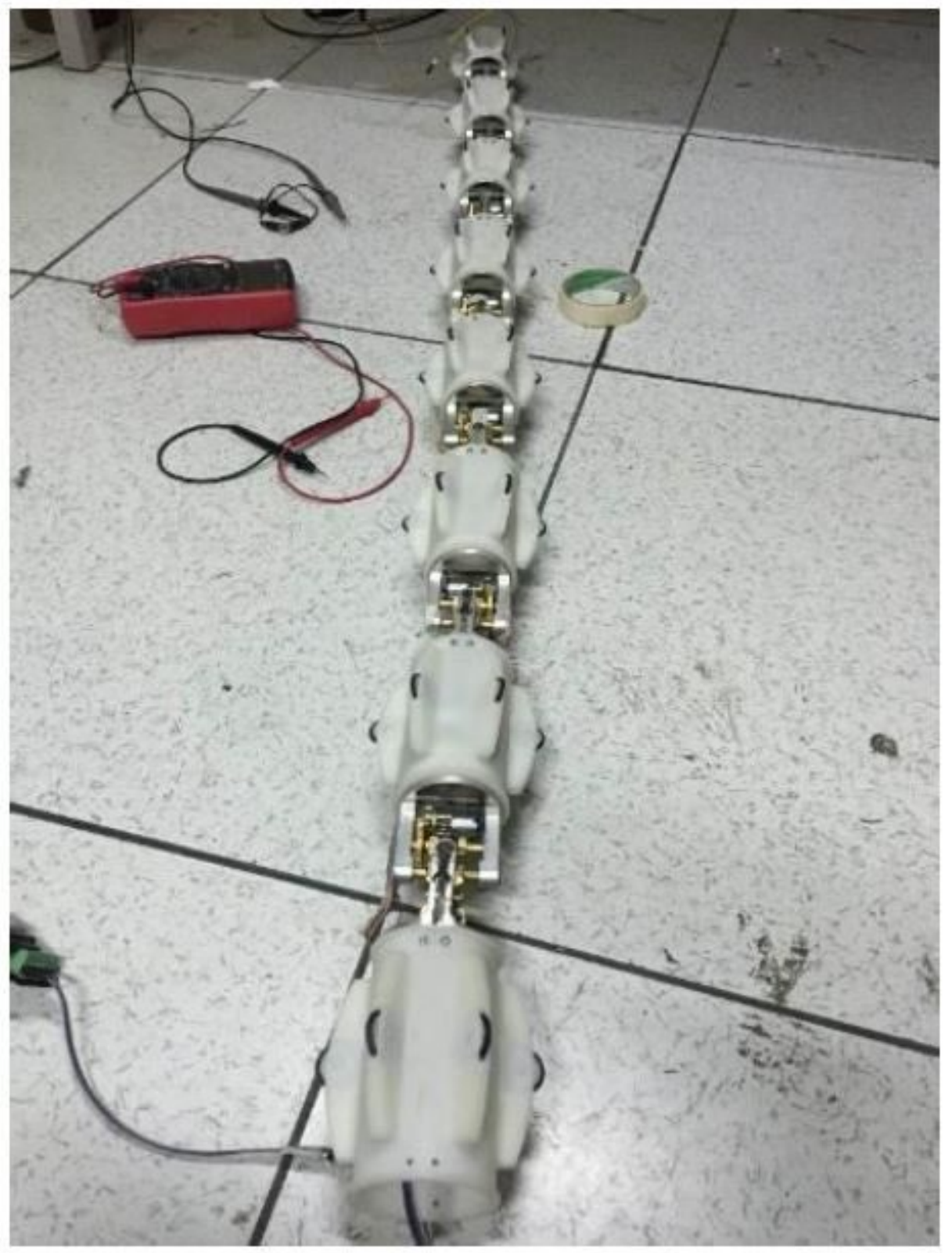

Figure 10

The prototype of the multi-joint snake robot 

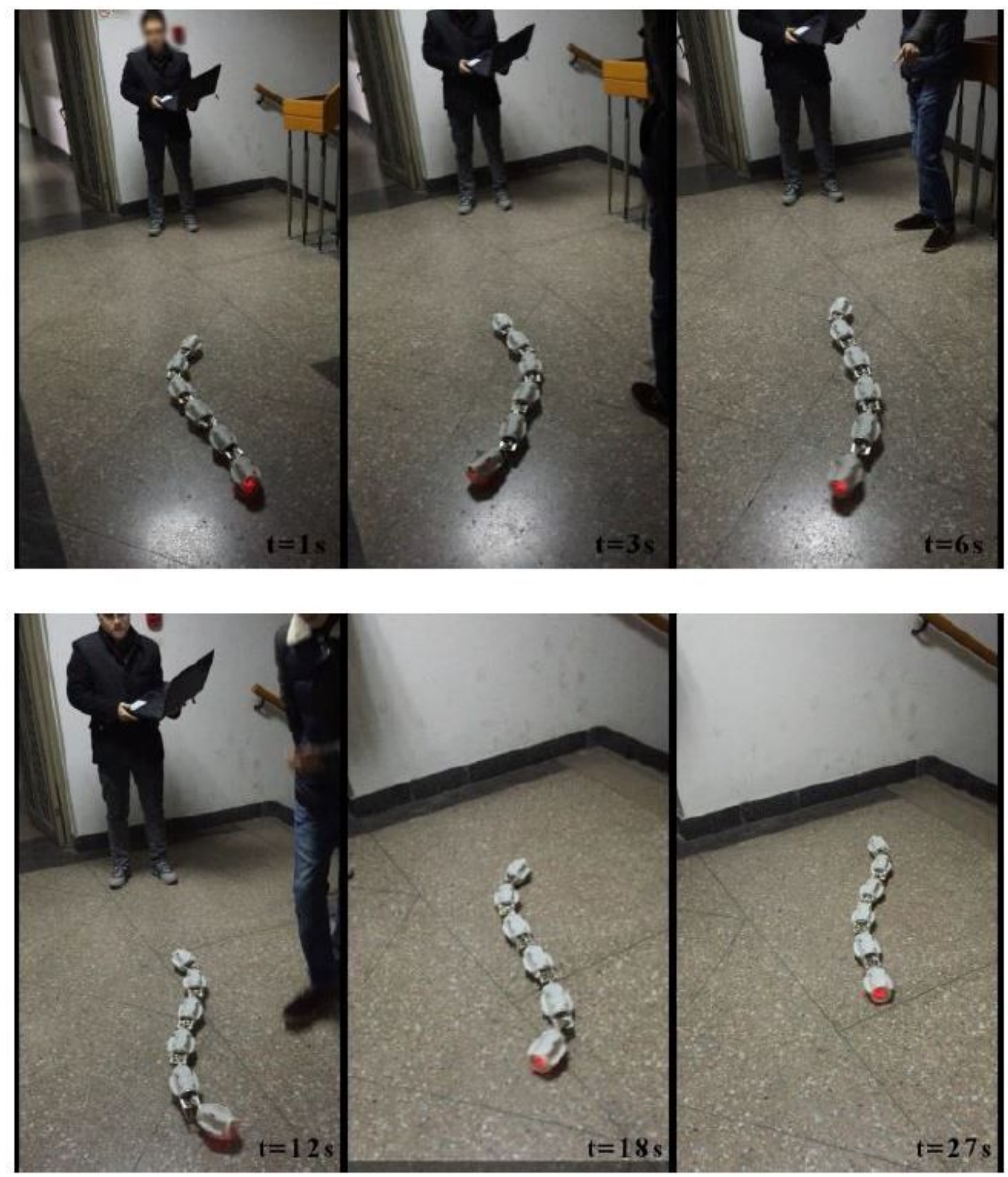

Figure 11

Prototype experiment 


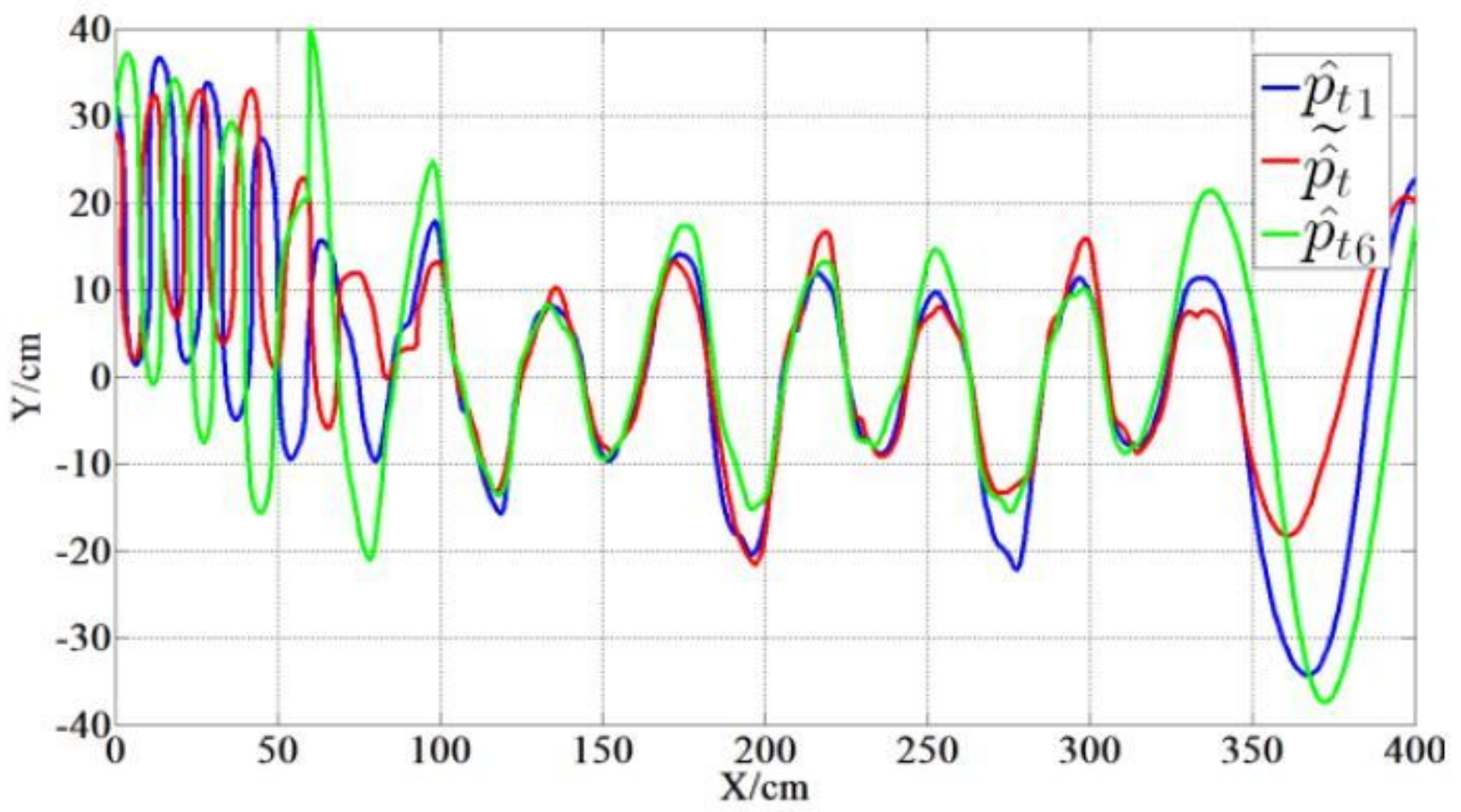

Figure 12

please see the manuscript file for the full caption 


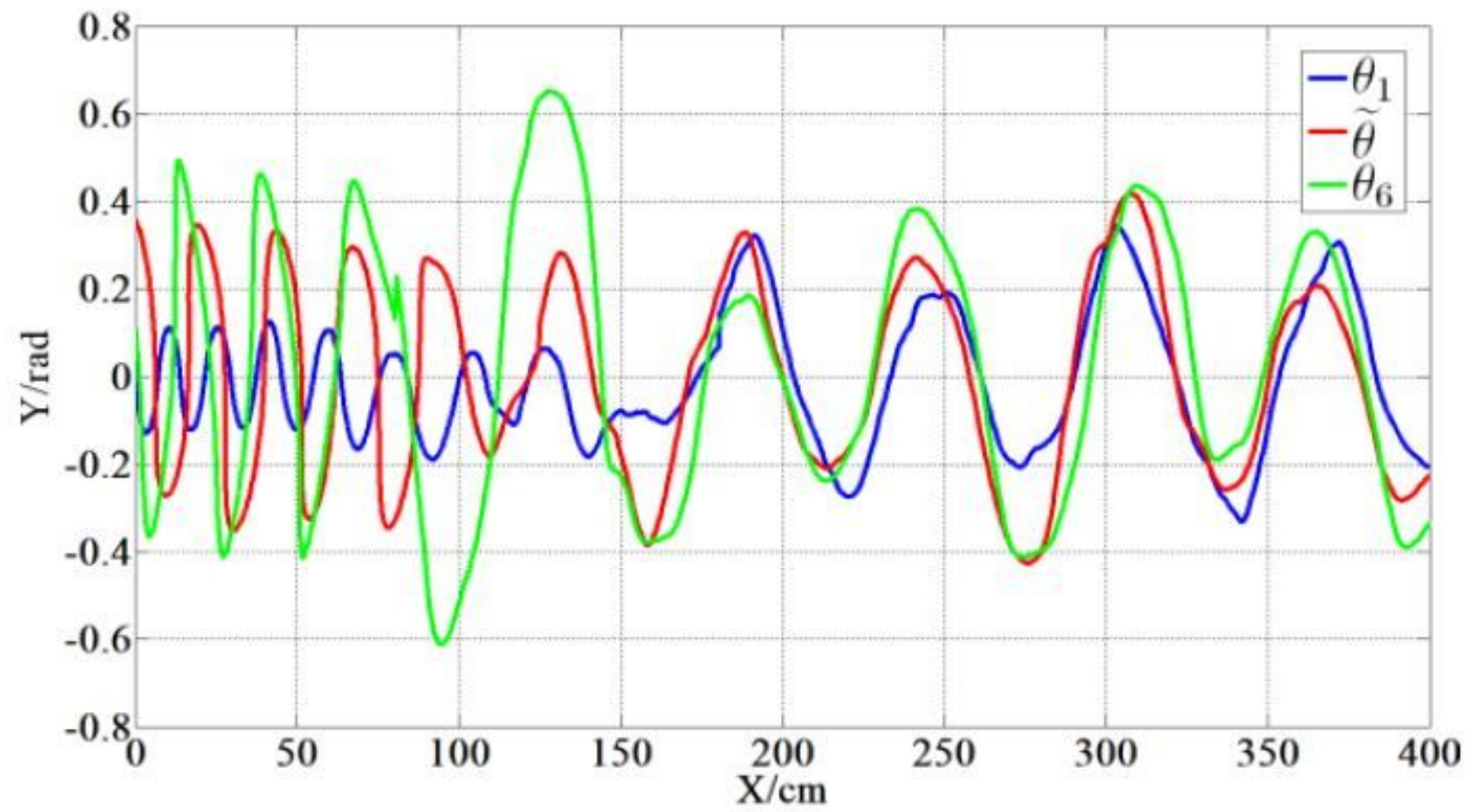

Figure 13

please see the manuscript file for the full caption 